\title{
Prolapsed cecoureterocele presented as a prenatal genital mass: A urological challenge
}

\author{
Roberto Méndez-Gallart, MD, PhD; Elina Estévez-Martínez, MD; Pablo Rodríguez-Barca, MD, PhD; \\ Maria García-Palacios, MD, PhD; Adolfo Bautista-Casasnovas, MD, PhD
}

Department of Pediatric Urology, Complexo Hospitalario Universitario de Santiago, Santiago de Compostela, Spain

Cite as: Can Urol Assoc J 2013;7(11-12):e757-60. http://dx.doi.org/10.5489/cuaj.497

Published online November 8, 2013.

\section{Abstract}

Prolapse of a cecoureterocele through the urethra presenting as a prenatal vulval mass is an extremely uncommon entity. We present a case of a newborn girl with a cecoureterocele extending through the urethra (diagnosed at 29 weeks' gestation) and we present its postnatal findings and outcomes.

\section{Introduction}

An ureterocele is a congenital saccular dilatation of the terminal portion of the ureter. They are 4 times more likely to occur in females. ${ }^{1}$ Ureteroceles in girls are associated with duplex systems in $95 \%$ of cases; in $80 \%$ of cases, they are associated with the upper pole of a duplex system. ${ }^{2}$ Cecoureterocele is an uncommon type of ureteroceles, where the blind pouch of the ureterocele is elongated beyond its orifice by tunnelling into submucosa under the bladder trigone and through the urethra. Perinatal prolapsing cecoureterocele is an unusual, but distinctive, sign that may present a diagnostic dilemma to the clinician and implies a challenge to pediatric urologist. ${ }^{3}$

\section{Case report}

A pregnant woman presented at 29 weeks' gestation for a routine prenatal sonography. Examination revealed 2 separate renal pelvises in the right kidney followed by dilatation of a single moiety with a dilated ipsilateral ureter and a thinwalled cystic mass within the bladder extending through the urethra. This finding was thought to represent an ectopic ureterocele. At 35 weeks of pregnancy, the cystic mass in the bladder was more prominent, extending outward between the fetal labia permanently. At 38 gestational weeks, the woman delivered a female infant. A newborn girl presented with a 2-cm cystic genital mass increasing in size during micturation (Fig. 1a, Fig. 1b). Postnatal ultrasound revealed a duplex right kidney with dilatation of the upper pole and ureterocele protruding into the urethra. Voiding cystourethrogram (VCUG) showed a well-defined contrasted tubular structure originated in the bladder with extension through the urethra, and vesicoureteral reflux (VUR) to the lower pole of the right kidney (Fig. 2). A magnetic resonance image (MRI) showed a markedly dilated right upper pole associated with a large ureterocele, outpouching from the urethra (Fig. 3 ). Right upper heminephrectomy of a dysplastic moiety and ureterocele aspiration were necessary. The postoperative course was uneventful, and the infant remains asymptomatic at the 2-year follow-up.

\section{Discussion}

A cecoureterocele prolapsing through the urethra is extremely uncommon. The incidence rate is less than $3 \%$ of all patients with ureterocele. ${ }^{4}$ It is more common in female infants and may be complicated by urinary obstruction and infection. ${ }^{5}$ To the best of our knowledge, there are only 3 reported cases of prenatal diagnosis of such an anomaly. ${ }^{6}$

Routine screening antenatal ultrasonography has dramatically increased the detection of urinary anomalies. To date, most babies with an ureterocele and duplex kidneys present antenatally. It is mandatory for pediatric urologist to recognize this anomaly and its prognosis. The report of an upper pole "cyst" in a fetus should be interpreted as being upper pole hydronephrosis until otherwise demonstrated. ${ }^{2}$

An extravesical ureterocele is a cause of bladder outlet obstruction in newborn girls. ${ }^{7}$ The clinical suspected diagnosis of an obstructing ureterocele should be considered in any female infant presented with intermittent stream, bladder 


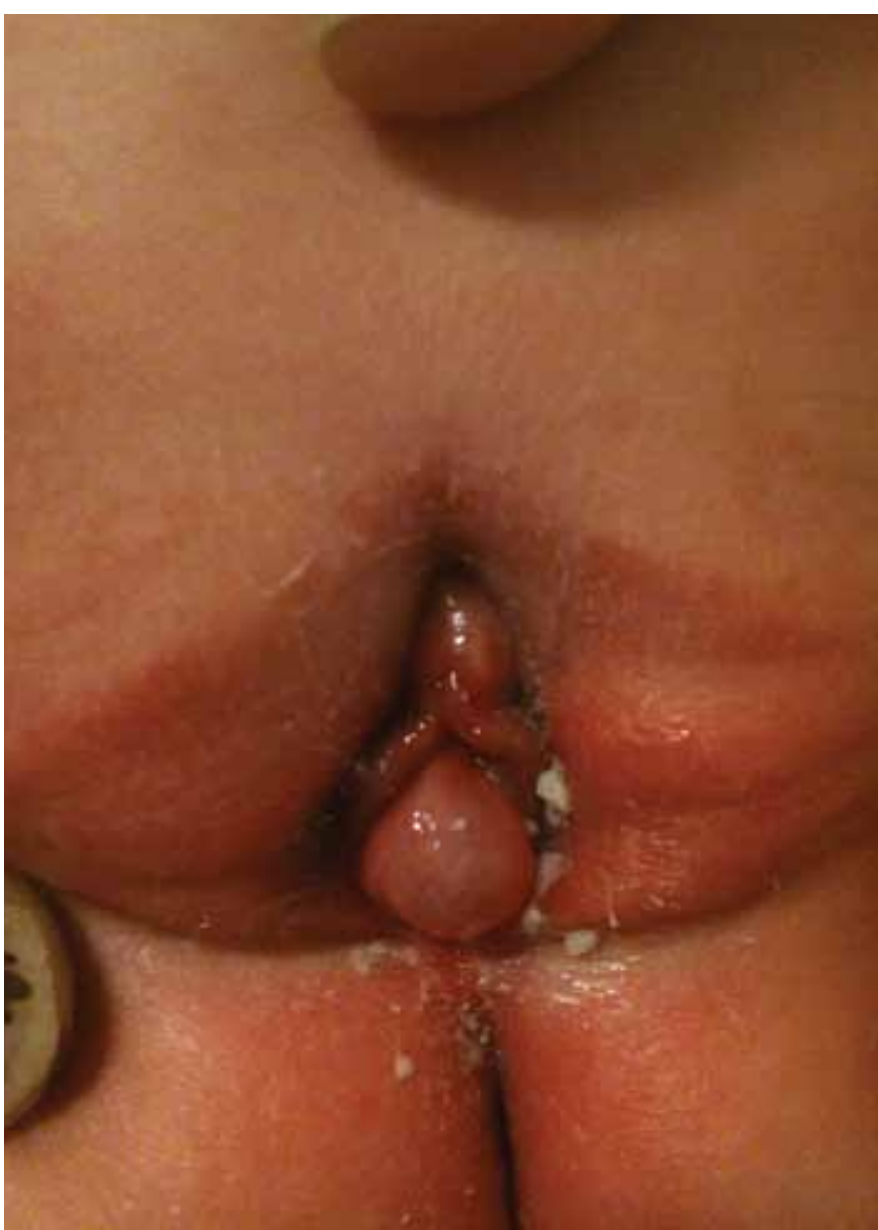

Fig. 1a. Genital picture of a newborn girl with a cystic mass protruding through the urethra before micturition.

distension, anuria, or ascites. Since prolapse occurs down the posterior wall of the urethra, it is common to encounter a congested, smooth, ecchymotic mucosa-covered genital cystic mass. Common complications of ureteroceles include urinary tract infection, obstructive voiding, urinary retention, failure to thrive, and abdominal pain. ${ }^{8}$

Ectopic ureteroceles present diagnostic dilemmas when it is difficult to determine from which renal moiety they arise. Ultrasound may be used initially to reveal a thin-walled cystic structure near the base of the bladder, dilatation of one or both moieties and associated duplex system. VCUG could accurately reveal the presence and severity of VUR and suggest ureterocele prolapse. The lower moiety ureter is often inserted more laterally and is prone to develop VUR. ${ }^{9}$ If diagnostic difficulty remains, then intravenous urography (IVU) and MRI may be used as accurate tools. IVU may demonstrate pelvi-calyceal anatomy and the ureterocele as a cystic intravesical-filling defect. ${ }^{8}$ MRI may demonstrate the extension of the ureterocele through the urethra and its association with a duplex system. ${ }^{6}$ As either of the moieties can be functioning poorly in a duplex system, a MAG-3

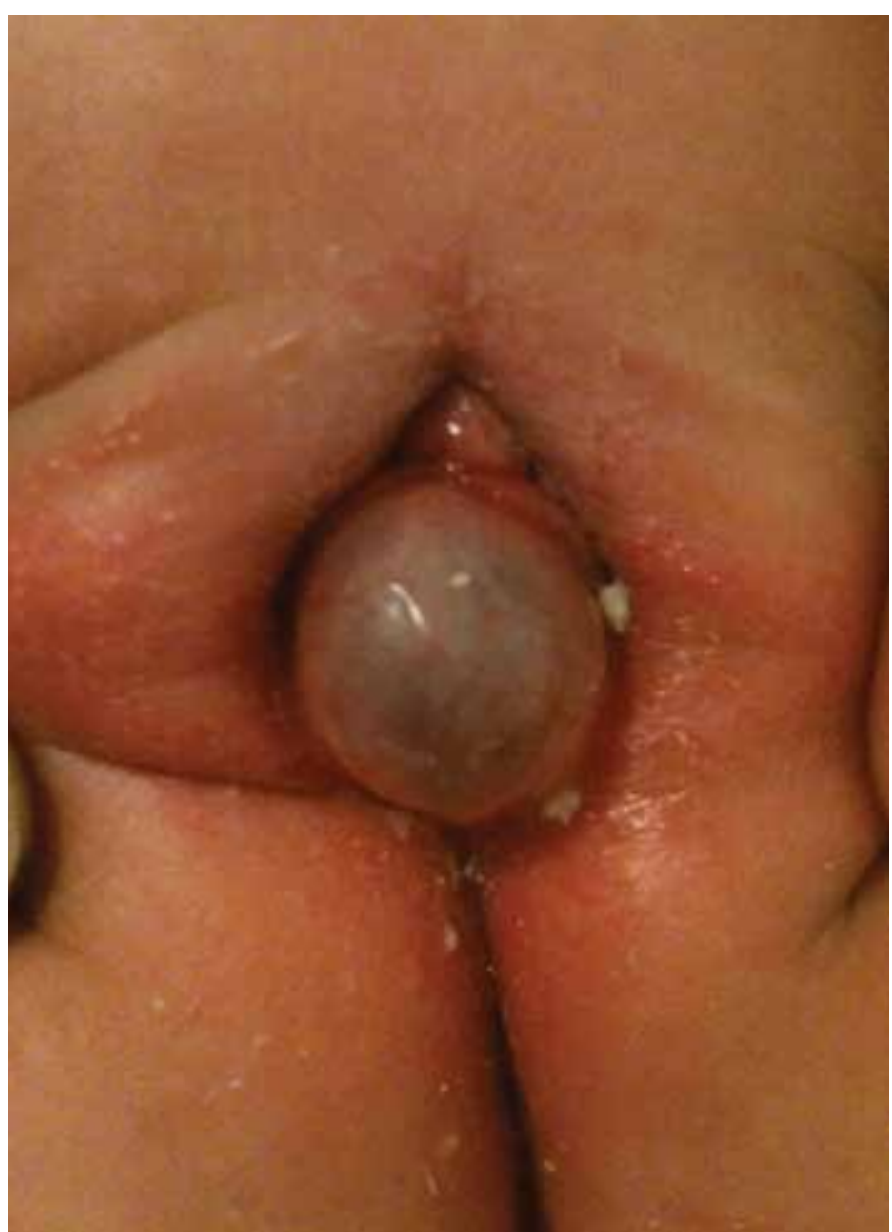

Fig. 1 b. Genital picture of the same newborn patient during micturition showing the increasing size of the prolapsed cystic mass.

isotopic renogram becomes useful for considering the different options in management. ${ }^{10}$ The differential diagnosis of a prolapsing cecoureterocele in newborns includes epidermal inclusion cyst, Skene's duct cyst, urethral prolapse, and sarcoma botrioides. ${ }^{1,3,7,8}$

Before surgery, we must obtain as much information as possible regarding the patient's altered anatomy. Although specific and definitive management for ureteroceles differ in some individuals, the goals of treatment are the same: preservation of renal function; prevention of infection, obstruction and reflux; and maintenance of urinary continence.

Management options of a ureterocele complicating a duplex kidney are diverse: conservative treatment, endoscopic incision, upper pole heminephrectomy, reimplantation of both ureters, and pyelopyelostomy. ${ }^{9-11}$ Each patient requires individualized treatment; nevertheless, upper pole removal is the preferred definitive procedure when there is clearly no function in the upper moiety. It may be accompanied by reimplantation of the refluxing lower pole ureter combined with ureterocele excision. ${ }^{11,12}$ In patients with a good upper pole function, the endoscopic puncture of ure- 


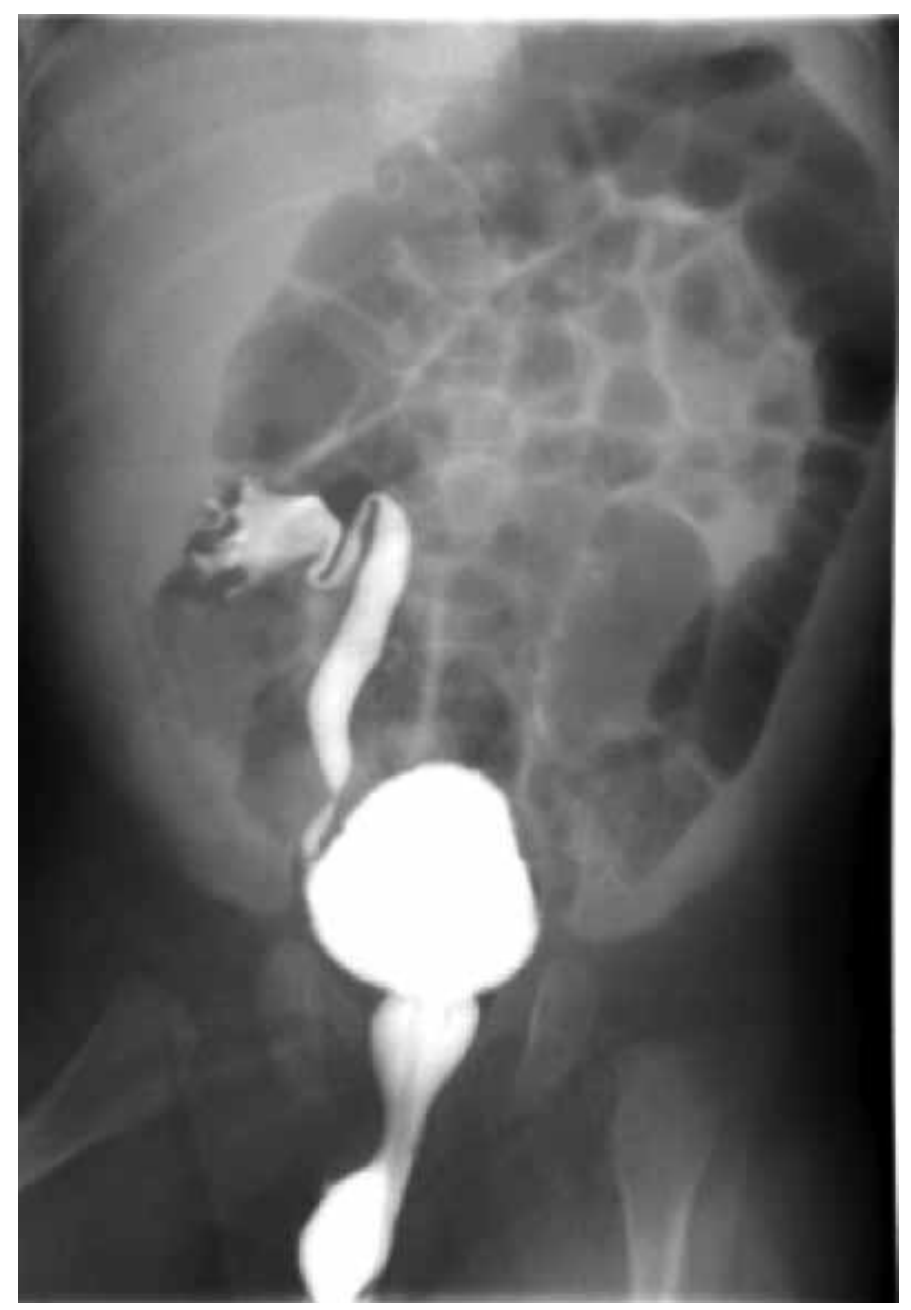

Fig. 2. Voiding cystourethrogram reveals a tubular structure originated in the bladder and extending to the urethra, and vesicoureteral reflux to the lower pole of the duplex right kidney.

terocele may be an attractive procedure despite the risk of creating reflux in the involved ureter. ${ }^{9}$ It has been reported that less than $20 \%$ of cases ultimately require secondary procedures for persistent VUR after primary treatment. ${ }^{9,12}$

\section{Conclusion}

A newborn with a prolapsing cecoureterocele provides an interesting challenge to the pediatric urologist. It may appear as a genital cystic mass in prenatal sonography. Ultrasound, IVU, VCUG and MRI may be necessary for adequate assessment. The anatomy and function of the system vary considerably and no one management plan is suitable for all cases. It is important to bear in mind that in these children it is possible to injure the bladder neck or damage a perfectly normal lower pole. Standard treatment is upper pole nephrectomy with aspiration of the ureterocele. Puncture of

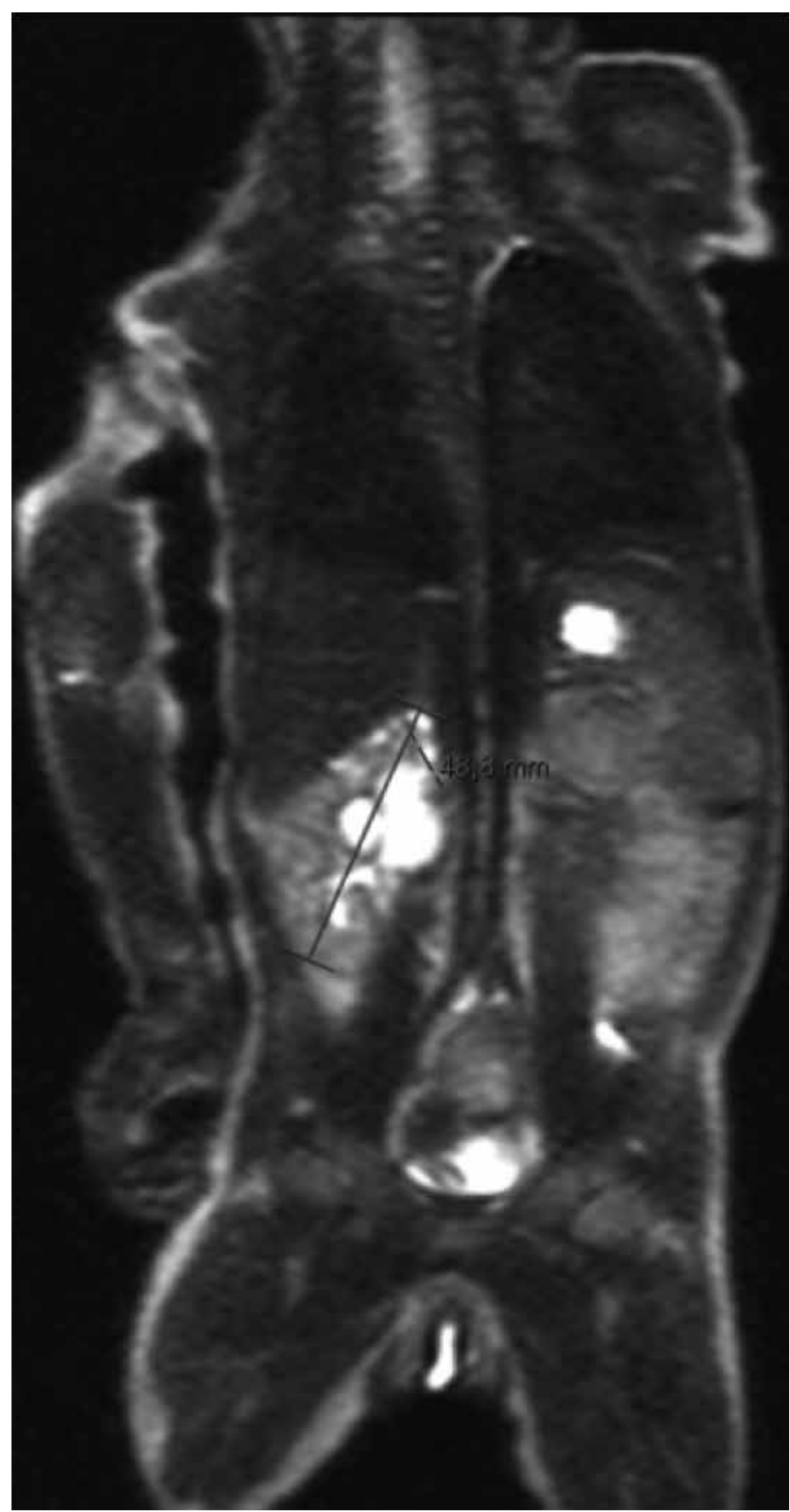

Fig. 3. Coronal T2-weighted magnetic resonance image showing a dilated right upper pole associated with a large ureterocele, outpouching from the urethra.

the prolapsed blind pouch of the cecoureterocele may be sometimes necessary.

Competing interests: Dr. Méndez-Gallart, Dr. Estévez-Martínez, Dr. Rodríguez-Barca, Dr. GarcíaPalacios and Dr. Bautista-Casasnovas all declare no competing financial or personal interests.

This paper has been peer-reviewed. 


\section{References}

1. Arrabal-Polo MA, Nogueras-Oca-a M, Tinaut-Ranera J, et al. Vulval tumor in an infant: prolapse of ureterocele. J Pediatr 2012;161:964. http://dx.doi.org/10.1016/i.peds.2012.05.055

2. Merlini E, Lelli Chiesa P. Obstructive ureterocele-an ongoing challenge. World J Urol 2004;22:107-14 http://dx.doi.org/10.1007/s00345-004-0407-y

3. Robson WL, Thomason MA, Newell RW, et al. Picture of the month. Ectopic ureterocele prolapsing through the urethra. Arch Pediatr Adolesc Med 1997;151:95-6. http://dx.doi.org/10.1001/archpedi.1997.02170380099017

4. Miller MA, Cornaby AJ, Nathan MS, et al. Prolapsed Ureterocele: a rare vulval mass. Br J Urol 1994;73:10910. http://dx.doi.org/10.1111/i.1464-410X.1994.tb07473.x

5. Klauber GT, Crawford DB. Prolapse of ectopic ureterocele and bladder trigone. Urology 1980;15:164-6. http://dx.doi.org/10.1016/0090-4295(80)90412-4

6. Sozubir S, Lorenzo AJ, Twickler DM, et al. Prenatal diagnosis of a prolapsed ureterocele with magnetic resonance imaging. Urology 2003;62:144. http://dx.doi.org/10.1016/S0090-4295(03)00152-3

7. Dénes FT, Lopes RN, Arap S, et al. Prolapsed ureterocele. Eur Urol 1985;11:106-9.

8. llica AT, Kocaoğlu M, Bulakbaşi $\mathrm{N}$, et al. Prolapsing ectopic ureterocele presenting as a vulval mass in a newborn girl. Diagn Interv Radiol 2008;14:33-4.
9. Jesus LE, Farhat WA, Amarante AC, et al. Clinical evolution of vesicoureteral reflux following endoscopic puncture in children with duplex system ureteroceles. J Urol 2011;186:1455-8. http://dx.doi. org/10.1016/i.juro.2011.05.057

10. Pohl HG. Recent advances in the management of ureteroceles in infants and children: why less may be more. Curr Opin Urol 2011;21:322-7. http://dx.doi.org/10.1097/MOU.0b013e328346d455

11. Chertin B, Fridmans A, Hadas-Halpren I, et al. Endoscopic puncture of ureterocele as a minimally invasive and effective long-term procedure in children. Eur Urol 2001;39:332-6. http://dx.doi. org/10.1159/000052463

12. Castagnetti $M$, Vidal E, Burei $M$, et al. Duplex system ureterocele in infants: Should we reconsider the indications for secondary surgery after endoscopic puncture or partial nephrectomy? J Pediatr Urol 2013;9:11-6. http://dx.doi.org/10.1016/i.jpurol.2012.06.016

Correspondence: Dr. Roberto Méndez-Gallart, Department of Pediatric Surgery \& Urology, University Hospital of Santiago, 15716. Avda. Choupana s/n, Santiago de Compostela, Spain; roberto. mendez.gallart@sergas.es 